\title{
Building Critical Community Engagement through Scholarship: Three Case Studies
}

\author{
Isobel M. Findlay, Marie Lovrod, Elizabeth Quinlan, Ulrich Teucher, \\ Alexander K Sayok, Stephanie Bustamante, Darlene Domshy
}

\begin{abstract}
Drawing on a shared recognition that community is defined, understood, constructed, and reconstructed through contextually inflected relationships, collaborating authors use diverse interdisciplinary case studies to argue that rigorous communityengaged scholarship advances capacities for critical pursuit of cognitive and social justice. Whether through participant-centred projects undertaken with youth in government care networks, cross-cultural explorations of Indigenous and non-Indigenous science and culture as resources for food security, or facilitated dramatizations of community relations impacted by neo-liberal ideologies, contributors affirm welcoming co-learning environments that engage multiple forms of knowledge expression and mobilization. The respectful spaces held in these community-researcher collaborations enable new advances beyond hegemonic knowledge development institutionalized through colonialist histories. This essay theorizes prospects for building transformative community through scholarship, citing practical examples of the principles and practices that foster or frustrate sustainable communities. It explores the institutional arrangements and power dynamics between and among actors, asking who gets included and excluded, and what boundaries are created and crossed around complex, contradictory, and contested notions of "community."
\end{abstract}

KEYWorDs community-engaged scholarship, food security, cognitive justice, decolonizing methodologies, participatory theatre

With the aid of three interdisciplinary case studies in local, national, and international contexts, this essay examines the different ways that "community" is defined, understood, constructed, and reconstructed by community-engaged and contextually inflected scholarship. If community-engaged scholarship has responded to concerns about overly detached universities needing to become more relevant and responsible (Smith, 1999; 2005), community both inside and outside universities has often been presumed to be unproblematically availableunusually singular, stable, and self-evident-for both study and action. The left and the right, individualist and collectivist traditions, all desire but cannot attain "exclusive title to community" (Findlay \& Findlay, 1995, p. 4). Similarly, community-university partnerships are often seen as panacea, glib guarantors of culturally and politically productive partnerships (Macdonald \& Chrisp, 2005). In other words, like community-university partnerships, community itself is insufficiently theorized. 
This essay aims to contribute to such theorizing, unpacking seductively familiar formulae, while exploring the successes and ongoing challenges of building transformative, critical community capacity through scholarship in three examples of the principles and practices that foster or frustrate sustainable communities in Canada and beyond. From researching in partnership with youth transitioning out of government care in Saskatchewan to rethinking food security within and across Indigenous and non-Indigenous worldviews to acting out and working through impediments to, as well as facilitators of, collaboration among sexual assault centres across Canada, contributors examine how community is continually redefined through engaged and engaging forms of research. This essay explores the institutional arrangements and power dynamics that enhance or inhibit comprehensive and culturally appropriate local engagement and decision-making via participatory action research (PAR) (Kemmis \& McTaggart, 2005; Stoecker, 2005). It asks who gets included and excluded, and what boundaries are created and crossed around complex, contradictory, and contested notions of "community," imagined and material (Anderson, 1991).

Communities survive and evolve, struggling and learning together to build and rebuild organizations and institutions. Individuals and organizations learn from each other in different ways. Sharing effective models as well as relevant and reliable knowledge is key to community success and sustainability. This essay focuses on decolonizing and democratizing knowledgebuilding with partner organizations and the broader communities they represent. It explores relational projects involving innovative knowledge-sharing strategies that transcend the theoryto-practice gap and stretch beyond academic journals and text-based processes of knowledge mobilization.

Community is understood here as a complex, dynamic system and field of action, as both social and physical space (Arce, 2003), with normative dimensions that signal belonging, acceptance, shared concern(s), and mutual interests (Bauman, 2001). Community is also a site for economic, political, and social projects that may reveal contested directions and objectives (DeFilippis, Fisher, \& Shragge, 2006). Community is where we negotiate differences of race, class, gender, sexual orientation, age, and ability that are more "dangerous trope" or "arbitrary constructs" than "reports of reality" (Gates, 1986, pp. 5-6). Yet metaphors or social constructions for which researchers are accountable prove at least as powerful as material conditions in shaping — for good and ill—our identities, realities, and any shared sense of the possible. If identities can be constructed, they can be reconstructed and conditions changed if we recognize "the central role of communications in building community cohesiveness within Aboriginal nations and fostering relationships between cultures. . . We actually construct who we are" (RCAP, 1996, pp. 620-621). Community is where we live and make a living, but it is also where we exercise capacity and commitments to "responsible renewal" (Findlay \& Findlay, 1995, p. 5), going beyond kinship and friendship in recognition and negotiation, confidence building and collaboration, through institutional and organizational innovation (Alperson, 2002). Sustainability is less about endpoints than re-imagined processes; it enables social learning and principled responses to emergent challenges and opportunities (Dyball, Brown, \& Keen, 2007).

Engaged Scholar Journal: Community-Engaged Research, Teaching and Learning 
If colonial research has been a destructive force- “complicit with ... imperial domination" (Battiste \& Henderson, 2000, p. 31) - we have opportunity and obligation to rewrite stories to "reright" relationships and realities (Smith, 1999; 2005) by unpacking the complicity of professional academic knowledges in producing and reproducing inequalities and injustice (Razack, 1998; 2002). Retelling the history of "disinterested" expertise-privileging Western scientific rationality as the exclusive route to narrowly defined progress, while disparaging and discounting Indigenous and other knowledges (Smith, 1999; 2005) — exposes a deplorable waste of lives, lands, voices, and knowledges (Bauman, 2004). This colonial process of knowledge building effectively produced a cognitive terra nullius where different epistemological, spiritual, territorial, and other dimensions of knowing were reduced to caricatures in the interests of intellectual speculation and practical exploitation of Indigenous land and labour (Findlay, 2014). This is why de Sousa Santos, Nunes, and Meneses (2007) argue that cognitive justice precedes social justice and why Tremblay, Hall, and Tandon (2014) promote "knowledge democracy" (p. 8). What Harding (2005) calls "strong objectivity" is impossible without inclusive accountabilities in knowledge production.

In step with de Sousa Santos and Harding, this essay shares our experience of rethinking research as a platform for building relationships within and across communities targeted too often by researchers, policy makers, and broader community as rich sources of data to be plundered (Smith, 1999) or as "problems" to be solved (Findlay \& Wuttunee, 2007). Those problems are typically articulated in terms of gaps, lags, or divides, in terms of a deficit model of Aboriginal people_-or youth (O’Dell, 2003) — in a legacy of colonial binary logic on which so much social and political theory is founded (Henderson, Benson, \& Findlay, 2000). Such thinking is, ironically enough, the legacy of "the epistemologies of ignorance" whereby the social contract has been defined by those who "count," their cognitive and cultural norms producing what has been called a "consensual hallucination" (Mills, 1997; cit. in Sullivan \& Tuana, 2007, pp. 3-4), which has proven especially hard to dislodge.

Decolonizing habitual thinking across public institutions is no small task and one that cannot be effected without both unpacking the colonial legacies and reclaiming Indigenous voices and vision (Battiste, 2000) in order to "nourish the learning spirit," resist "cognitive imperialism," re-imagine Aboriginal-non-Aboriginal relations, and remake our world in holistic ways (Battiste, 2013). If the "tragic experience of colonization is," as Daes (2000) reminds us, "a shared experience," then oppressor as much as oppressed is in need of healing (p. 6) and we share the need and obligation to re-imagine in engaged scholarship who we are and would like to be.

Re-imagining sustainable communities is urgent in the face of the often contradictory and confounding effects of globalization and neoliberalism (Bauman, 1998). Collectively, these processes contribute to trade liberalization, deregulation, and governments downloading social responsibilities to individuals and targeted communities, resulting in uneven development in both universities and communities. Community-based organizations (CBOs) experience government downsizing and offloading as increased demands to partner in order to meet growing needs without adequate resources (Cooper, 2007). Citizens-Aboriginal and non- 
Aboriginal alike-experience funding decisions as "subjective, made by distant bureaucrats with no knowledge of local realities" and find few opportunities to be heard (Women's Economic Council, 2010, p.ii; Chandler, Lalonde, Sokol, \& Hallet, 2003). These processes promote voter skepticism, alienation, and low civil society participation (Federation of Canadian Municipalities, 2008), while simultaneously forcing groups to find new ways to work together for survival.

Attempts to re-imagine and reclaim governance (Ostrom, 2009) also reflect a growing sense that collaborating and partnering are fraught activities often doubling as alibis for neoliberalism. Instead of the uncritical assumption that partnering will solve all problems, partnership dynamics need probing. This includes links among structure, power, and process, as well as tensions between leadership and partnership, among different partner objectives, among the complex politics of partnership within which partner cultures often remain invisible or underestimated (MacDonald \& Chrisp, 2005). Like "community," "partnership" is a term that needs to be read for presumption as well as reassurance if we are to get at the roots of problems rather than aggravating domination and entrenching business as usual (Cornwall \& Brock, 2005; Tremblay, Hall, \& Tandon, 2014) and if we are to support effective "place-based learning communities" (Davidson-Hunt \& O'Flaherty, 2007, p. 291).

While the literature is clear on barriers to equitable engagement in partnerships, our community-engaged research paints a picture of collective accountability for factors that foster or frustrate healthy, sustainable communities. Our community partners demand a role in governance and the recovery of voice and choice-of self-determination-as a key part of relearning positive situated selfhood and making a sustaining and sustainable life narrative. They also underline the persistently gendered challenges and the need for co-operative and intergenerational restitution of relations to self, community, and land, underlining our collective responsibility to all of creation, including all that it sustains and is sustained by. Each of the case studies presented here speaks to the challenges and opportunities, the enormous investments of time and talent, as well as the rich rewards of trusting relationships built in the research process.

\section{Case Study 1. Partnering with Youth: Rebuilding Community Capacity}

The history of youth in care and custody in Canada is — in part—an effect of persistent public disengagements from targeted communities. Social stratifications established in the process of colonialist nation-building continue to produce measurable impacts on quality of life and learning, along lines of tenacious social inequities and constructed differences (Battiste \& Henderson, 2000). Because the young have been construed as the primary responsibility of female care-givers in Canada, disproportionate concentrations of neglected and abused children are a strong indicator of neglected and abused women, families and communities, who live with enduring social injustice at the intersections of race, class, gender, disability, citizenship status, and expressions of sexual and gender diversity. Such "big picture" awareness means little, however, when a young person is "apprehended" into government care or custody. Immediate challenges are too pressing to support sustained reflection on such difficult circumstances as

Engaged Scholar Journal: Community-Engaged Research, Teaching and Learning 
produced socio-historical effects, a life-story likely shared with many others.

The university-community partnership with the Saskatchewan Youth in Care and Custody Network (SYICCN) which grounds this case study reflects a commitment to mutuality in research design and delivery that seeks to repair social bridging capacity (Odora Hoppers, 2008), even where bonds may have been stretched_-sometimes to the breaking point_-by barriers to fair and equitable access to opportunity. One measure of such deferred actualization can be seen in the significant numbers of youth in and from government care who, for myriad reasons, do not complete public, let alone post-secondary educations. If universities, colleges, and technical training centres are, among other things, class-climbing institutions (Smith, 1990), hierarchical social systems have functioned efficiently to divert many youth in care from advanced education, and to construct educational environments as unresponsive to their learning needs. How might community-engaged research reverse low educational attainments among youth in care and custody, particularly in a province where Aboriginal youth are over-represented? How might such efforts help to change educational practices and power dynamics?

Modest gains have been made. Increasingly, university students themselves recognize the absence of peers from care and are demanding change. Student unions at both Saskatchewan universities have joined other Canadian counterparts in pressing for tuition waivers for qualifying youth in and from government care. This welcome gesture of allegiance currently represents limited institutional investment, owing to the few young people from care who are encouraged to view post-secondary training as an option. Too often, such ambitions are discouraged; youth from out-of-home care are constructed as too "damaged" to aspire to higher education, even though it is clear that multiple disruptions in living arrangements during formative years contribute to uneven preparation for post-secondary learning opportunities. Significant skills for coping with the chaos that failures of cognitive and social justice produce may also result.

Classified as a vulnerable population, youth in care are commonly perceived as a difficult group with whom to develop public knowledge in rigorous research, given received interpretations that personalize structural deficits. However, in a series of initiatives undertaken together with SYICCN leadership, collaborative faculty, student, and youth-led research teams have identified favourable conditions for research conducted with, by, for, and about youth in and from government care and custody. These efforts include supporting young people to negotiate their own research agendas; recognizing that research design need not be overly complex or invasive; and appreciating frameworks that affirm the aspirational energies of young people, rather than bolstering the "harm narrative" (O'Dell, 2003), which distorts public discourse about child welfare through target blaming. Youth appreciate research projects that welcome their voices in processes that are fun, transformative and rewarding, and researchers learn at least as much as the young people do in the process. When constructive, peer-supported knowledge-building relationships lead to healthy naming of challenges that participants have faced or can expect, no attempts are made to erase, diminish, or sweep under the rug, any of those lived experiences, positive or negative. The point is to honour youth choices in framing individual and shared life events and conditions_- "nothing 
about us without us" - without adopting tired scripts that serve adult agendas.

Established in 1991-92, SYICCN is a non-profit, community-based network of distributed local youth groups, connected through an arms-length provincially-funded office in Regina. Where community supports have been systematically undermined among those most impacted by social disparities, youth attempt to rebuild connections among themselves and wider constituencies, including with adults who co-learn how to build respectful, ethical, youthcentred research around topics chosen by youth themselves. Affiliated with a national umbrella organization (Youth in Care Canada [YICC]) which connects provincial networks through research initiatives and conferences, SYICCN has developed clear youth-centred protocols for evaluating potential research and other partnerships.

SYICCN members stay in contact with local, provincial, and national networks through email, Facebook, text messaging, biennial conferences, and adult supports who keep provincial leadership informed about emerging issues/opportunities. In provinces where many foster families live in rural communities, youth who stand out among peers as wards of the state flourish in the company of compadres to whom nothing need be explained; all understand what it means to have government as custodial parent.

Past research collaborations at the national level have included a report for the Federal Advisor on Child Sexual Abuse; research on the challenges of teen parents in and from care; and a study on the overuse of psychotropic medication among youth in government care (Lambe, et al., 2009). The provincial network has, meanwhile, contributed to Saskatchewan's Child Welfare Legislative Review, conducted research with the Council for Children, and met with the Minister of Social Services to outline evidence-based proposals for action. As a result, Saskatchewan held its first "Child and Youth in Care" week in 2014, profiling the positive potentials of young people in and from care. A direct intervention in the stigmatizing stories that still circulate in public imagination, this event is one of several successes arising from recent research collaborations. Baseline funding for the network has been stabilized, and onetime funds to hire a part-time research coordinator were recently awarded by the province.

Every aspect of the research we conduct together is generated with network members, in order to develop age-appropriate research questions crafted by and with young people. When youth have direct input into the design and completion of research, they are better able to convey clear responses to questions that make sense to them, and are more invested in research outcomes. They also develop confidence presenting research results in appropriate venues.

The title of our first longitudinal baseline study, Our Dream, Our Right, Our Future (SYICCN, 2011), was generated in a youth focus group. Methods used were proposed, designed, and vetted with and by youth. One of the first lessons we learned together was that surveys are less fruitful than creative expression through photo-voice, scrap booking, and community mapping, in part, because coming to language about lives disrupted by removals to "the system," is not always easy. Collaborative right-brain activities support young people to "find the words" in safe spaces created among youth and supportive adults. These methodological techniques have taught us that dialects of dominance have too often underestimated and obscured the voices of young people, who have a strong grasp on their own best interests, and

Engaged Scholar Journal: Community-Engaged Research, Teaching and Learning 
on practical ways of sharing their ideas within youth networks and to wider public audiences. Creative inquiry can be corrective and healing when protection has undermined participation among youth in care.

Remembering and making meaning from lives that do not follow an expected pattern requires supportive community (Campbell, 2003). In fact, YICC has argued that peer networking creates a subculture where youth learn together to navigate sometimes traumatic, sometimes restorative experiences. Early plans to co-create a guide for healthy transitions from care included basic recipes for healthy meals interwoven with strategic life-skills information, a survival resource since updated for the computer age. An enduring coping strategy operates through resilient use of dark humour through which youth in care reach for laughter, while articulating the challenges they face.

Once an affirmative peer-support network has been established, it becomes possible to engage in more sustained story-telling practices such as oral histories, digital stories, and collective co-biographies, which need not over-personalize systemically reproduced forms of social ignorance, neglect or abuse. Rather, iterative and cumulative spaces that welcome youth voice and vision enhance shared awareness of how interruptive structures can be re-imagined as surmountable. Community-based research, then, becomes a resource in youth development, reframing tensions as potentially productive, even when difficult to navigate. As one member of the organization's leadership team has remarked, the network is a healing environment because it is a shared learning environment where, in the face of difficulties and error, it is possible to "try again." As young people strive to learn through community-engaged research how best to transition toward more inclusive forms of adult citizenship, they demonstrate that trajectories shaped by historical inequities need not be surrendered to them. Rather, by building on collaborative, creative approaches to knowledge construction, capacities to imagine new ways of being are supported, through more nourishing configurations of community.

\section{Case Study 2. Indigenous Food Knowledge: Hybrid Modes of Existence?}

Food security is another arena where modern colonialist science has produced and legitimized cognitive injustice (de Sousa Santos, 2007). Two-thirds of World development schemes, instead of creating justice and equality, have become "a continuation of war by other means against marginals, tribals and peasants" (Visvanathan, 2007, p. 337). This section casts some light on struggles for food security faced by Indigenous peoples, in Malaysia and Saskatchewan.

Global threats to food security are well-rehearsed: our world population will reach 9 billion by 2050 while we have been losing biodiversity, arable lands, and traditional nutrition sources, and struggling with food production and distribution. Today, only three crops-wheat, maize, and rice-provide $60 \%$ of the world's carbohydrates; of 7000 known food plants, only about 120 account for $90 \%$ of all plants used for nutritional purposes (CFFRC, 2011).

The usual agricultural research response to these problems has been to try increasing the yields of our global major crops, supported by economically expensive and environmentally destructive agro-chemicals (Patel, 2009; Shiva, 2013). Research at the Malaysian Crops for the Future Research Centre (CFFRC, 2011) has been taking paths less trodden, studying instead 
the thousands of underutilized food plants in local environments, with findings to be shared in broad databases. Arguably, since much of the knowledge of underutilized food plants has been in the provenance of the world's Indigenous peoples (Balick \& Cox, 1996), food security studies might best document and preserve this Indigenous knowledge of biodiversity in the interests of the survival of Indigenous peoples and of the cultural commons of humanity. However, several impediments have kept the West from considering such knowledge-from engaging with and learning from Indigenous peoples and communities as important knowledge experts (Visvanathan, 2007; Teucher, 2010).

\section{Positivistic Food Studies}

Non-indigenous food research has, historically, approached food more or less as an instrumental means for biological survival. However, humans have used food not only for survival but for many symbolic purposes:

Everything about how humans eat has meaning: who is allowed to fish for it, mill it, or kill it; what vessels and utensils are used in the preparation; what time of day the meal is eaten; who sits where at the table (if you're eating at a table), how close to an important person, a certain food, the salt, a person of anther gender, race, or class; what order the food is served in; who serves it; whether it is hot or cold, cooked in water or by direct fire. (Citivello, 2008, p. xiv)

Further, many Indigenous peoples have often viewed food resources, including food plants, as sentient beings enlivened with spirits with whom human beings share familial relationships and responsibilities. For example, Canadian Métis people view flora and fauna, in terms of evolutionary history, as older, more knowledgeable brothers and sisters on whom we depend, can converse with, and should treat with respect (Dorion, 2011). Similarly, for Malaysian Indigenous peoples, the world, including each leaf of grass, is filled with sentient spirits, some amenable, others quarrelsome, who must be respected so as not to incur bad harvests, illness, or death (Nuek, 2005; B. Dowel, personal communication, June 2012). Rice was - and still often is - treated as if it had a soul. Long lists of rituals prescribe how rice fields should be chosen (considering omens), cultivated, harvested (cutting only at prescribed angles), rice eaten (for example, not letting rice fall through floor boards), and always retaining some food for the ever-present spirits (Biswas, 2003). Non-indigenous researchers are often ignorant of, and thus seen as disrespectful towards, such modes of existence, practices, and rituals where food resources are seen as agentic beings and voices in dialogue with humans and the environment (Bierwert, 1999). Where Western eyes may see only subsistence farming to be overcome, indigenous food practices reveal cultural systems and epistemologies that are central to social participation (Visvanathan, 2007) and to cognitive justice (de Sousa Santos, 2007).

\section{Culture Change/Loss of Indigenous Knowledge}

Much traditional Indigenous knowledge, including food and food plant knowledge, has 
been lost, eliciting calls for its restoration (Hansen, 2014; Morrison, 2011). In West Malaysia, where Indigenous communities have no title to their lands, land development (e.g., oil palm plantations) and industrialization have been displacing communities, pressing them to abandon traditional hunting and gathering and assume day labour in nearby factories. Confronted with different local environments, and knowledgeable elders dying out, these hunters and gatherers often can no longer apply and hand down their traditionally oral knowledge (Nicholas, 2000), unable to recite even the first lines of their once many traditional stories and songs. Such knowledge loss has been raising questions about whether artifacts and once lived practices and rituals should, or even can, be usefully preserved in cultural centres or museums or be taught in schools. Yet many Malaysian Indigenous peoples appreciate some cultural changes such as the ban on headhunting, the reduction of superstition, and the possibility that Indigenous mothers about to give birth can be flown by helicopter from the jungle to the nearest clinic, significantly decreasing birth mortality. Some Indigenous members have acceded to the highest positions in Malaysian society and politics, serving as respected ambassadors overseas, while others, perhaps ironically, may be involved in logging companies that clear primary and secondary forests for oil palm plantations. In any case, how does change affect their traditional knowledge systems? In the interest of cognitive justice, can Indigenous and non-indigenous ways of knowing, including food knowledge, enrich one another?

\section{Hybrid Ways of Knowing and Modes of Existence?}

Scholars have mapped different cultural knowledge systems (Battiste, 2000; Battiste \& Henderson, 2000; Beeman \& Blenkinsop, 2008; Derbyshire, 2014; Kusch, 2010; Settee, 2013; Teucher, 2010). Yet Indigenous researchers in particular have been expressing the hope that the differences between Indigenous and non-indigenous ways of knowing can be reconciled in order to solve common environmental challenges (Hansen, 2014; Morrison, 2011). For example, the members of the Métis community of Beauval (Saskatchewan) embrace traditional ways of knowing, while employing technological solutions (such as greenhouses) to grow crops locally and reduce long distance food transportation. Members of the Malaysian Bidayuh community Peninjau Lama seek to preserve traditional knowledge while embracing farming strategies from their Chinese neighbours; some of the former work as biodiversity scientists at Universiti Malaysia Sarawak.

Indeed, there seems to be common ground between Western and Indigenous ways of knowing (Balick \& Cox, 1996; Teucher, 2010). For example, Indigenous knowledge has always been carefully empirical, relying on systematic observations of patterns of continuity and change in the environment (Kidwell 1992). Until the advent of colonialism, American Aboriginal technological knowledge and application was on par with Western cultures (boat technology or watering systems) before being left out of the benefits of the emerging technological revolution (Kidwell, 1992; Teucher, 2010). Philosopher of science Bruno Latour (2014) may well have taken Indigenous ways of knowing into account when he invests his different "modes of existence" (humanity, science, environment) with creative agentivity in their mutual interrelations. Such "ecological interwovenness" (Beeman \& Blenkinsop, 2008) 
may make possible new hybrid modes of knowing. Moreover, a comprehensive science of biodiversity, the environment, and cultural food practices may well create the space and new, vital rituals for an overall awareness, spiritual or secular, of the fragility of our planet, the transiency of life, and our human responsibilities not to squander our planet's limited resources. These emergent rituals might provide novel points of connection between Indigenous and Western ways of knowing_-growing out of an ethics of respect and cognitive justice.

\section{The Engaged Scholarship Project: Partnering Saskatchewan and Sarawak}

An interdisciplinary approach to food security studies driven by cognitive justice might bring together Indigenous knowledge experts (from communities and academic institutions) and researchers from food security institutes, even across seemingly incompatible modes of existence. In exploratory work with the Malaysian CFFRC, we have assisted in creating an innovative crop database of thousands of understudied crops, including bio-botanical, nutritional information, and cultural knowledge associated with each plant. In addition, we have had conversations with 31 Indigenous knowledge experts in remote as well as urban communities and at universities, and we have undertaken a pilot study of ethno-botanical food plant knowledge at the Indigenous Bidayuh community of Peninjau Lama in Sarawak, Malaysia. Indigenous knowledge experts and participants have shaped the preliminary research and interview guide questions, as well as the selection of food plants for an educational poster. Bidayuh artists, shamans, a sociologist, biodiversity experts, and graduate students have all helped us appreciate Bidayuh sociocultural knowledge and cosmovison with regard to food plant knowledge. Currently, we are building contacts in Saskatchewan, including the Beauval Métis community and Global Institute for Food Security, for a partnership with Malaysia, based on the same engaged principles. As ethnobotanists Balick and Cox (1996) have noted, the relationships between plants and people are profound, affecting nearly every aspect of our lives. The very roots of human culture are deeply intertwined with plants-in particular the plants that we eat.

\section{Case Study 3. Using Participatory Theatre to Explore Challenges to Collaboration among Community-Based Organizations}

In the context of the chronic underfunding of community-based organizations addressing aggravated social and economic inequalities in Canada, collaboration among these organizations is increasingly necessary, but also made more difficult. This case study describes participatory theatre techniques used with local community-based organizations to explore barriers and facilitators to successful collaborations.

The impetus for the participatory theatre session was a project on attributes of effective campus-community partnerships in sexual assault survivorship and advocacy (Quinlan, Clarke, \& Miller, 2013). The project was undertaken in the wake of a high profile sexual assault on the local campus that made evident to institutional leaders and activists alike the need to foster durable relationships between campus and community groups. Recommendations emerging from the project's pan-Canadian scan of collaborations between community organizations 
and campus sexual assault and/or women's centres focused on improvements to the local university's procedures on sexual assault prevention, advocacy, and care. Other outcomes of the analysis were more generic in nature and audience: all community-based organizations, whether addressing homelessness, poverty, or food insecurity, can relate to the shrinking government funding and escalating human need.

The campus-community boundary was the particular divide explored in the project; however, there are many others, most rooted in organizations' differing resources and status. Because these divisions abound, the community-based organizations represented at the session had a stake in exploring collaboration and examining the attendees' role, behaviours, and actions in facilitating and impeding their organization's collaborations with other CBOs. Despite the shared stakes and laudable intentions, who of us wants to consider ourselves as part of the problem? How do we explore our own role in the re/production of the deleterious social interactions and imagine alternative social structures among and within communitybased organizations? How do we investigate these questions without giving further voice to hegemonic ideologies? Required was a form of collective problem-solving that offered the safety of representational forms connected to, yet separate from, participants' existential realities: a process that short-circuits cerebral censorship; a protected space where participants can activate their experiential knowledge and 'rehearse' actual dilemmas with emotional authenticity but without real life consequences. Enter participatory theatre, stage left.

Participatory theatre (PT), an embodied form of social learning, is based on critical performance theory, a dialectic of Brecht's modernist liberatory tradition combined with postmodern dramaturgy's unresolved narratives and multiple stages and actors (Boje, Luhman, \& Cunliffe, 2003). Participatory theatre takes inspiration from the Boalian tradition (Boal, 2000; 2002) of theatre empowering individuals to become protagonists in their own lives by recognizing that social problems can be experienced individually but have structural antecedents. Participatory theatre's explicitly political ambition is for oppressed groups to seize the means of aesthetic production, to occupy the stage in order to radically transform society. Currently, participatory theatre endorsed by UNESCO to generate social change is being used in over 70 countries (UNESCO, 1997).

In participatory theatre, tableaus and short scenarios are developed by a core group of (non-actor) participants that reflect the underlying stories of their everyday lived experiences. By working through the body, participants' tacit, common-sense knowledge is made transparent through the group experience. No previous acting training is required and only a minimum of sets, props, and costumes. To confront the cultural hegemony of elite theatre, participatory theatre facilitators often need to assure participants that everyone-those with or without training or "talent" — can take part. Our session's facilitator opened the session by affirming the experiential knowledge present in the room was the only expertise necessary:

This isn't Hollywood. In this setting, authority comes from our experience, whether that experience is working in a CBO. We are drawing on our experience as volunteers, executive directors, or in other roles working with organizations broadly 
defined as pursuing social change. The aim of what we do today is to express as many different points of view as possible for our collective consideration.

Very quickly, we were active. The participants were out of their chairs and engaging in a series of games to de-mechanize our response patterns, create group cohesion, and relate the embodied experiences to aspects of cross-CBO collaboration (Boal, 2002).

PT's explicit intention is to hone participants' creative capacities, to envision new social structures, and create non-hierarchical social relationships. In this way, participatory theatre stands in contrast to the function of psychodrama, which evokes catharsis for therapeutic purposes (Moreno, 1947). The transformative potential of participatory theatre lies in its power to ignite participants to recognize their shared interests, envision alternative social orders, and address identified barriers collectively. Participatory theatre mobilizes knowledges for the explicit purpose of dismantling systems of oppression and creating a more equitable, sustainable world.

Our participatory theatre session proceeded with the carnival activity. In groups of three, each member took a turn making a repetitive movement and accompanying sound, continuing long enough for the other group members to learn it. Then, without speaking, the group formed a singular movement and sound, morphed from the elements of the three precursors. Once the group-specific movement and accompanying sounds were solidified, the groups amalgamated theirs with the other groups using the same silently negotiated process: the groups of three formed groups of six, then groups of 12 and, eventually, a single group of 24. The end of the activity was signaled by a unified room in which everyone was moving and sounding together.

The carnival was a site of individual and group acts of reflectiveness and creative responses to the dominant social and economic order within which community-based organizations operate. It enlivened participants' capacities to self-consciously interpret social arrangements that impede collaboration and to imagine new, alternative normative structures that support collaboration. In the post-carnival discussion, participants connected their experience in the activity with cross-boundary collaborations. For instance, one participant remarked that the game revealed her tendency to reject others' initiatives or proposals for action and resist emerging consensus in multi-organization meetings. Long after most in the room were moving in unison, she held out with her own motion and sound, rallying for them to adopt what was hers rather than conceding to the group will.

In the session's final activity, participants took turns creating tableaus that reflected their experience of an unsuccessful collaboration. The tableaus were built from the sculpting clay of the bodies of other participants and then used as collectivized social experiments in which new characterizations and outcomes were investigated. In the discussion that followed, participants were invited to reflect on their roles, life scripts, and the hegemonic narratives represented in the tableaus. The enactments uncovered essential truths of $\mathrm{CBO}$ contexts without resorting to spoken language. The ensuing dialogical interactions arising from the theatrical constructions gave participants control over the social construction of meaning, their own identities, and the

Engaged Scholar Journal: Community-Engaged Research, Teaching and Learning 
development of a 'moral community.' Mutual understandings were forged based on recognition of participants' shared values of social justice. Tacit assumptions and unwritten rules about how community-based organizations should function were articulated and challenged for their disabling effects: adoption of corporate staffing models, dogged reliance on government funding, and 'othering' CBOs with differing mandates.

Based on the recognition that we are all responsible for uprooting social injustices and that it is possible for agents of oppression to reinvent themselves as agents of liberation, participatory theatre tackles the unlearning of embedded historical patterns of dominance (Mindell, 1995). However, because it has no choice but to work within the oppressive systems it intends to sunder, participatory theatre is never free of contradictions. The dialectic relationships between actors and audiences and $\mathrm{CBO}$ directors and staff they represent must be interrogated simultaneously. The very structures of domination are operating while we work to dismantle them. Giving equal airtime to racist, homophobic, misogynistic views in the protected space of a participatory theatre workshop perpetuates the very power structure participatory theatre aims to unseat. The perennial tension between the imperative to disrupt hegemonic knowledges and the democratic impulse to let all voices be heard falls to the facilitator to negotiate.

Rendering the status quo visible is the first step to collectively imagining, enacting, and assessing alternative social orders. The session's CBO representatives investigated the ideological legitimation of the current climate of competition among organizations for limited funding sources through their embodied ways of knowing. Participants' experiential knowledge in dynamic, multiple interactions gave way to an emergent collective identity, a heightened sense of validation, agency, and understanding of new potentials.

\section{Conclusions}

Networks, research teams, and communities are built through interpersonal and intergroup connections that may help to re-negotiate and re-imagine commonalities on the one hand, or bind resources to power systems that mine and undermine capacities for belonging and cooperation, on the other. Rarely are these processes mutually exclusive. Rather, variously imagined communities seek ways to balance the powers that accrue to collective accountabilities and their failures with the potentials that are enabled and disabled by past and emergent configurations of social relations.

Each case study attempts to hold accommodating space for expression and re-articulation of relationships that have been distorted by unjust power-differentials, often advanced during imperialist (knowledge) processes that still undergird contemporary globalization. Whether grounded in the intersectional forms of domination that produce relational distortion among community-based organizations; or in the aspirations of young people displaced to government care; or in pursuing cross-cultural understanding to facilitate responsible food security, each of these community-university projects stretches the terms of engagement toward greater inclusion and elasticity of knowledge frameworks. Working across disciplines and layers of power relations, each contributor uses research platforms that support communities to 
resituate their understandings of social relations in order to advance cognitive and social justice. By affirming that all voices and knowledges count in any rigorous scholarly response to the challenges humanity faces, each case promotes relationality as a resource in knowledge creation.

Participants bring to the table of knowledge development issues requiring creative modalities ranging from visual expression and ritual to interactive play in order to challenge the primacy of the written word as a privileged site for knowledge development and dissemination. Refusing to sever cognitive from social, spiritual, and cross-cultural domains, each community project negotiates evolving forms of co-creative knowledge development.

These three cases show research to be less about "discovery" than reconstituting communities in the research process and recognizing accountability for the interventions we make and the learning and outcomes we generate together. It is about growing respect for the reciprocity associated with "All my relations." Adopting flexible timelines, investing additional resources, and obtaining diverse input, our research seeks to decolonize itself for rich community building results. Universities are still learning how to live up to communitybased research values by adjusting entrenched specializations, tenure and promotion standards, and collaborative goal setting in order to permit genuine commitments to community-engaged scholarship. Mono-disciplinary journals are rarely the site of cutting-edge work in this area or of professional practices to support knowledge mobilization that is useful to community and consistent with "reporting back" responsibilities (Smith, 1999, p. 15). The mutual learning in participatory action research benefits community by unleashing individual and collective knowledge and heightened capacities for agency, understanding, and innovation. It benefits the university in developing methodological theory and practice, as well as pedagogy and curricula that better serve those who might be more fully engaged in education and governance.

\section{Acknowledgements}

The authors would like to thank all the community and university research partners who have contributed so much to understanding cognitive justice; staff and participating members of the Saskatchewan Youth in Care and Custody Network; the Indigenous communities in the village of Peninjau Lama, at the University of Malaysia Sarawak, and in the capital Kuching (all Borneo); the $\mathrm{CBO}$ representatives and other participants at the participatory theatre workshop held at Station 20 West, Saskatoon.

\section{About the Authors}

Stephanie Bustamante is the Executive Director of the Saskatchewan Youth in Care and Custody Network, and a collaborator on a joint research project: Youth in Transit: Growing out of Care. She brings a background in youth involvement in the criminal justice custody system and in domestic violence prevention and response. 
Darlene Domshy is Research Coordinator for the Saskatchewan Youth in Care and Custody Network. Former Director, she brings a decade of experience leading the organization to the project of youth-centered research.

Isobel M. Findlay (corresponding author) is a professor, Management and Marketing, Edwards School of Business; University Co-Director, Community-University Institute for Social Research; and Fellow, Centre for the Study of Co-operatives, University of Saskatchewan. She publishes widely on Aboriginal and associative organizations; communications, cultures, and communities; partnerships and participation; and transcultural law and justice. Email: findlay@edwards.usask.ca

Marie Lovrod is Assistant Professor and Coordinator, Women's and Gender Studies, University of Saskatchewan. Her research focuses on youth trauma and resiliency in the context of government care, on the impacts of intersectional identity and social positioning on youth life-chances, and on the effects of aging among women. She values communities of practice that respect research, learning, and inclusive spaces.

Elizabeth Quinlan is an Assistant Professor in the Department of Sociology at the University of Saskatchewan. Her research on workplace health, caring labour, and gender relations employs arts-based strategies to engage participants from the outset through to innovative knowledge translation.

Alexander Sayok is an Indigenous Bidayuh Associate Professor at the Institute of Biodiversity and Environmental Conservation, Universiti Malaysia Sarawak, Malaysia. He has been researching multidisciplinary aspects of community forests, assisting local Indigenous communities to develop ownership and make decisions on the conservation and sustainable use of their forests.

Ulrich Teucher is Associate Professor in the Program for Culture, Health, and Human Development, University of Saskatchewan. His research has been exploring events of transition and crisis, including serious illness (e.g., cancer) or cultural disruptions among Indigenous peoples in Canada and Malaysia (e.g., loss of food knowledge).

\section{References}

Alperson, P. (2002). Introduction: diversity and community. In P. Alperson (Ed.), Diversity and Community: An Interdisciplinary Reader (pp. 1-30). Malden, MA: Blackwell.

Anderson, D. (1991). Imagined communities: Reflections on the origin and spread of nationalism. London: Verso. Arce, A. (2003). Re-approaching social development: A field of action between social life and policy processes. Journal of International Development, 15, 845-861.

Balick, M. J., \& Cox, P. A. (1996). Plants, people, and culture: The science of ethnobotany. New York: Scientific 
American Library.

Battiste, M. (2000). Reclaiming Indigenous voice and vision. Vancouver: UBC Press.

Battiste, M. (2013). Decolonizing education: Nourishing the learning spirit. Saskatoon: Purich Publishing Ltd.

Battiste, M., \& Henderson, J. Y. (2000). Protecting Indigenous knowledge and heritage: A global challenge

Saskatoon: Purich Publishing.

Bauman, Z. (1998). Globalization: The buman consequences. New York: Columbia University Press.

Bauman, Z. (2001). Community: Seeking safety in an insecure world. Cambridge, UK: Polity Press.

Bauman, Z. (2004). Wasted lives: Modernity and its outcasts. Cambridge, UK: Polity Press.

Beeman, C., \& Blenkinsop, S. (2008). Might diversity also be ontological? Considering Heidegger, Spinoza and Indigeneity in educative practice. Encounters on Education, 9, 95-107.

Bierwert, C. (1999). Brushed by cedar, living by the river: Coast Salish figures of power. Phoenix: University of Arizona Press.

Biswas, R. R. (2003). Malaysia: Riches from the golden land. Vienna: Springer Verlag.

Boal, A. (2000). Theatre of the oppressed. London: Pluto Press.

Boal, A. (2002). Games for actors and non-actors. (A. Jackson Trans.). London: Routledge.

Boje, D., Luhman, J., \& Cunliffe, A. (2003). A dialectic perspective on the organizational theatre metaphor. American Communication Journal, 6(2), 1-16.

Campbell, S. (2003). Relational remembering: Rethinking the memory wars. Maryland: Rowman and Littlefield.

CFFRC (2011). Crops for the future research centre: Beyond food security. Semenyih, MY: University of Nottingham Malaysia Campus.

Chandler, M., Lalonde, C., Sokol, B., \& Hallet, D. (2003). Personal persistence, identity development, and suicide. Boston, MA: Blackwell.

Civitello, L. (2008). Cuisine and culture: A history of food and people. Hoboken, NY: John Wiley and Sons.

Cooper, M. (2007). Pathways to change: Facilitating the full civic engagement of diversity groups in Canadian society. Calgary: Guyn Cooper Research.

Cornwall, A., \& Brock, K. What do buzzwords do for development policy? A critical look at 'participation,' 'empowerment,' and 'poverty reduction.' Third World Quarterly, 26(7), 10431060.

Daes, E.-I. (2000). Prologue: The experience of colonization around the world. In M. Battiste (Ed). Reclaiming Indigenous Voice and Vision. (pp. 3-8).Vancouver: UBC Press.

Davidson-Hunt, I.J., \& O'Flaherty, R.M. (2007). Researchers, Indigenous peoples, and place-based learning communities. Society and Natural Resources, 20(4), 291-305.

DeFilippis J., Fisher, R., and Shragge, E. (2006). Neither romance nor regulation: Re-evaluating community. International Journal of Urban and Regional Research, 30, 673-689.

Derbyshire, P. (2010). Andeanizing philosophy: Rodolfo Kusch and indigenous thought. Radical Philosophy, 163 (Sep/Oct), 34-42. Retrieved from http://www.radicalphilosophy.com/article/ andeanizing-philosophy

De Sousa Santos, B. (2007). Cognitive justice in a global world: Prudent knowledges for a decent life. Lanham, UK: Lexington Books.

De Sousa Santos, B., Nunes, J. A., \& Meneses, M.P. (2007). Introduction: Opening up the canon of knowledge and recognition of difference. In B. de Sousa Santos (Ed.). Another Knowledge Is Possible: Beyond Northern Epistemologies. (pp. xix-lxii) New York: Verso.

Dorion, L. M. (2011). Relatives with roots: A story about Métis women's connection to the land. (R. Flamand

Engaged Scholar Journal: Community-Engaged Research, Teaching and Learning 
[Michif-Cree], Trans.). Saskatoon: Gabriel Dumont Institute.

Dyball, R., V. Brown, M. Keen. (2007). Towards sustainability: Five strands of social learning. In A. E. J. Wals (Ed). Social Learning: Towards a Sustainable World. (pp. 181-194). The Netherlands: Wageningen Academic Publishers.

Federation of Canadian Municipalities. (2008). Quality of life reporting system. Retrieved from http:// www.acaciaconsulting.ca/fcm/qolrs/10x10grid.htm.

Findlay, I M. (2014). "Nuna is my body": What Northerners can teach about social cohesion. In B. Fairbairn \& N. Russell (Eds.). Co-operative Canada: Empowering Communities and Sustainable Businesses. (pp. 41-64). Vancouver: UBC Press.

Findlay, I.M., \& Wuttunee, W. (2007). Aboriginal women's community economic development: Measuring and promoting success. IRPP Choices, 13(4), 1-26.

Findlay, L. M., \& Findlay, I.M. (Ed. \& Inrod.). (1995). Realizing community: multidisciplinary perspectives. Saskatoon: Humanities Research Unit and Centre for the Study of Co-operatives.

Gates, H.L. (1986). Editor's introduction: Writing 'race” and the difference it makes. In H. L. Gates (Ed). "Race,” Writing, and Difference. (pp. 1-20). Chicago: U of Chicago P.

Hansen, A. (2014). Food security and sovereignty in Beawval, Saskatchewan. Unpublished manuscript, International Centre for Northern Governance and Development, University of Saskatchewan.

Harding, S. (2005). Rethinking standpoint epistemology: What is "strong objectivity"? In A.E.Cudd \& R.O. Andreasen (Eds). Feminist Theory: A Philosophical Anthology. Oxford: Blackwell.

Henderson, J. Y., Benson, M.L., \& Findlay, I.M. (2000). Aboriginal tenure in the constitution of Canada. Toronto: Carswell.

Kemmis, S., \& McTaggart, R. (2005). Participatory action research. In N.K. Denzin \& Y.S. Lincoln (Eds.), Handbook of Qualitative Research (3 ${ }^{\text {rd }}$ edition). (pp. 559-603). Thousand Oaks, CA: Sage.

Kidwell, C. S. (1992). Systems of knowledge. In A. M. Josephy, Jr. (Ed.), America In 1492: The World of The Indian Peoples Before the Arrival of Columbus (pp. 369-403). New York: Alfred A. Knopf.

Kusch, R. (2010). Indigenous and popular thinking in America. Trans. M. Lugones \& J. M. Price. Durham, NC: Duke University Press.

Lambe, Y., McLennan, R., Manser, L., Andrews, Y., \& Bentzen, C. (2009). Drugs in our system: An exploratory study on the chemical management of Canadian systems youth. Ottawa: National Youth in Care Network.

Latour, B. (2014). An inquiry into modes of existence: An anthropology of the moderns. (C. Porter, Trans.) Cambridge, MA: Harvard University Press.

Macdonald, S., \& Chrisp, T. (2005). Acknowledging the purpose of partnership. Journal of Business Ethics, 59(4), 307-17.

Mindell, A. (1995). Sitting in the fire: Large group transformation using conflict and diversity. Portland, OR: Lau Tse Press.

Moreno, J. L. (1947). The Future of man's world. New York: Beacon House.

Morrison, D. (2011). Indigenous food sovereignty: A model for social learning. In H. Wittman, A. A. Desmarais, \& N. Wiebe (Eds.), Food Sovereignty in Canada: Creating just and sustainable food systems. Halifax: Fernwood Publishing.

Nicholas, C. (2000). The Orang Asli and the contest for resources: Indigenous politics, development and identity in Peninsular Malaysia. Copenhagen, DK: IWGIA International Working Group for Indigenous Affairs. 
Nuek, P. R. (2005). A Dayak Bidayuh community: Rituals, ceremonies and festivals. Kuching, MY: Lee Miing. O’Dell, L. (2003). The "Harm" story in childhood sexual abuse: Contested understandings, disputed knowledges. In P. Reavey \& S. Warner (Eds.). New Feminist Stories of Child Sexual Abuse: Sexual Scripts and Dangerous Dialogues. New York: Routledge.

Odora Hoppers, C. (2008). Lifelong learning Iin Africa: Lessons, experiences and opportunities from cultural and cognitive justice. [oral presentation] UNESCO, 29 October. http://unesdoc.unesco. org/images/0016/001636/163618e.pdf.

Ostrom, E. (2009) A general framework for analyzing sustainability of social-ecological systems. Science, July 24, 2009: 419-22.

Patel, R. (2009). The value of nothing: Why everything costs so much more than we think. Toronto: Harper Perennial.

Quinlan, E. Clarke A., and Miller, N. (2013). Coordinating and enhancing care and advocacy for sexual assault survivors: New collaborations and new approaches. Saskatoon: Community-University Institute for Social Research.

Razack, S. (1998). Looking white people in the eye: Gender, race, and culture in courtrooms and classrooms. Toronto: U of Toronto Press

Razack, S. (Ed.). (2002). Race, space, and the law: Unmapping a wbite settler society. Toronto: Between the Lines. Royal Commission on Aboriginal Peoples. (1996). Gathering strength. Volume 3. Ottawa: Minister of Supply and Services Canada.

SYICCN Inc. (2011). Our dream, our right, our future: Voices from Saskatchewan's youth in care and custody network. Foreword M. Lovrod. Regina: SYICCN Inc. Retrieved from http://www.syiccn.ca/ documents/

Settee, P. (2013). Pimatisiwin: The good life, global Indigenous knowledge systems. Vernon, BC: J. Charlton Publishing.

Shiva, V. (2013). Making peace with the Earth. Halifax: Pluto Press.

Smith, D. E. (1990). Texts, facts, and femininity: Exploring the relations of ruling. London: Routledge.

Smith, L. (1999). Decolonizing methodologies: Research and Indigenous peoples. London: Zed Books.

Smith, L. (2005). On tricky ground: Researching the Native in the age of uncertainty. In N. K.

Denzin \& Y. S. Lincoln (Eds.), The Sage Handbook of Qualitative Research (3rd ed.) (pp. 85-108). Thousand Oaks, CA: Sage.

Stoecker, R. (2005). Research methods for community change: A project based approach. Thousand Oaks, CA: Sage. Sullivan, S., \& Tuana, N. (Eds.). (2007). Race and epistemologies of ignorance. Albany: State University of New York.

Teucher, U. (2010). Aboriginal health research and epidemiology: Differences between Indigenous and Western knowledge. In T. McIntosh, B. Jeffery, and N. Muhajarine (Eds.), Redistributing Health: New Directions in Population Health Research in Canada (pp. 57-63). Regina, SK: CPRC Press.

Tremblay, C., Hall, B., \& Tandon, R. (2014). Global trends in support structures for community university research partnerships. UNESCO Chair in CBR. Retrieved from http://unescochair-cbrsr.org/ unesco/pdf/IDRC_Survey_Results_2014.pdf.

UNESCO (1997). The UNESCO courier. November, 1997. Paris: UNESCO.

Visvanathan, S. (2007). An invitation to a science war. In B. de Sousa Santos (ed.), Cognitive Justice in A Global World: Prudent Knowledges For a Decent Life. (pp. 337-352). Lanham, UK: Lexington Books.

Women's Economic Council. (2010). If women mattered: The case for federally funded women-centred community economic development. Ontario: Women's Economic Council.

Engaged Scholar Journal: Community-Engaged Research, Teaching and Learning 